\title{
LAS EMOCIONES SURGIDAS ANTE UN INCIDENTE CRÍTICO EN EL ÁMBITO DEL LIDERAZGO EFICAZ: ESTUDIO COMPARATIVO ENTRE DIRECTIVOS NOVELES Y EXPERTOS
}

\section{Oscar Nail ${ }^{1}$, Jorge Valdivia ${ }^{2}$, Darío Rojas ${ }^{3}$ y Carles Monereo ${ }^{4}$}

\section{RESUMEN}

La investigación busca analizar la emocionalidad del directivo novato y experto cuando se produce un incidente crítico, es decir, una contingencia inesperada y desestabilizadora en la organización escolar. El diseño corresponde a un estudio de casos de carácter interpretativo, donde se analizaron las emociones que están en la base de las decisiones que adoptan los directivos en situaciones críticas. La recogida de datos consideró técnicas de investigación social a través de los grupos focales, los cuales permitieron captar las emociones experimentadas por los directivos de una manera más vívida y dialógica ante un incidente crítico, complementada con una bitácora digital en línea en la que se formalizó el registro del incidente crítico asociado al directivo y la relevancia de las emociones surgidas al enfrentar dichas situaciones imprevistas. Los resultados mostraron que existen diferencias entre un directivo novel y uno experto al momento de enfrentar un incidente crítico: los primeros manifestaron una mayor percepción negativa de las emociones surgidas ante el incidente, mientras que los directivos expertos realizaron una mayor reflexión y mostraron más preocupación por la comunidad escolar. El directivo novel evidenció un manejo conductual mayormente supeditado a la preocupación por su trayectoria profesional y el cuidado de su imagen como autoridad.

Conceptos clave: actores, directivo, emoción surgida, incidentes críticos, organización escolar.

\section{EMOTIONS THAT ARISE WHEN FACING A CRITICAL INCIDENT IN THE FIELD OF EFFECTIVE LEADERSHIP: COMPARATIVE STUDY BETWEEN NOVEL AND EXPERT DIRECTIVES}

\section{ABSTRACT}

The research seeks to analyze the emotional response of the novice and expert school leader when a critical incident occurs, that is, an unexpected and destabilizing contingency in the school organization. The design corresponds to a case study of an interpretative nature, where the emotions that are at the base of the decisions made by directors in critical situations were analyzed. The data collection considered social research techniques through focus groups, which

1 Universidad de Concepción, Concepción, Chile. Contacto: onail@udec.cl

2 Universidad de Concepción, Concepción, Chile. Contacto: jvaldivi@udec.cl

3 Universidad de Concepción, Concepción, Chile. Contacto: dariorojas@udec.cl

4 Universidad Autónoma de Barcelona, Barcelona, España. Contacto: carles.monereo@uab.cat 
allowed capturing the emotions experienced by directors in a more vivid and dialogic way, when confronted with a critical incident, complemented by an online digital logbook in which the registry of the critical incident associated with the leader and the relevance of the emotions that arise when facing such unforeseen situations. The results found showed that there are differences between new and expert leaders when facing a critical incident. Novice directors, unlike experts, expressed a greater negative perception of the emotions that arose before the incident. In addition, expert directors made more meaningful reflections and showed more concern for the school community, whereas, the new director exhibited behaviors mostly motivated by concern for one's professional career and protecting one's image as an authority figure.

Key concepts: actors, critical incidents, directive, emotional response, school organization

\section{Introducción}

El liderazgo es un tema recurrente en la comunidad educacional debido a la influencia que este ejerce en las prácticas docentes, la determinación de los objetivos institucionales, el desarrollo profesional de los profesores, la promoción de prácticas pedagógicas efectivas y la colaboración en la resolución de conflictos en el aula (Anderson, 2011; Bolívar, 2009; Elmore, 2010; Hallinger \& Heck, 1998; Leithwood, Day, Sammons, Harris, \& Hopkins, 2006; Robinson, Hohepa \& Lloyd, 2007; Waters, Marzano \& Mcnulty, 2003).

En el mismo contexto, Uribe y Celis (2012) señalan que la figura del director adquiere gran relevancia al hablar de calidad en la educación. A su vez, ahondan en el quehacer de los directivos, en la definición y clasificación de aquellas competencias que el directivo tiene o debe movilizar para ejercer su rol y contribuir a la mejora escolar. A partir de esta mirada, existe un amplio consenso en señalar que, para desarrollar conductas de liderazgo eficaces, con impacto en los procesos de enseñanza y aprendizaje, es preciso mejorar los conocimientos, habilidades y disposiciones de los directivos a través de la formación y el desarrollo profesional.

En relación con la preparación de líderes escolares, distintos estudios indican que esta debe desarrollarse durante todas las etapas de la carrera de un director (Pont, Nusche \& Moorman, 2008), identificando al menos tres momentos relevantes para la formación: 
inicial, de inducción y continua. La literatura indica que, respecto de la formación de estos líderes, existe la necesidad de diferenciar la oferta formativa atendiendo al momento de la carrera en el que se encuentre el director (Bush \& Jackson, 2002; Darling-Hammond, LaPointe, Meyerson, Orr \& Cohen, 2007).

\section{El manejo emocional y situacional del directivo}

Una necesidad que se reconoce como transversal durante la trayectoria profesional del director es el manejo de las relaciones y el clima que se produce entre los diferentes actores de la comunidad escolar, por lo que buena parte del liderazgo eficaz está asociado con la toma de decisiones y la resolución de problemas no estructurados (Leithwood, 2009), articulando la reflexión personal con las acciones y ampliando el entendimiento de estas últimas (West-Burnham $\&$ Ireson, 2005). De esta forma, los procesos de desarrollo de líderes directivos implican dar cuenta de las capacidades y habilidades de autoconocimiento, autorregulación y automotivación, habilidades que se desarrollan a través de procesos formales e informales, involucrando elementos conversacionales en torno a las situaciones problemáticas (Rodríguez, 2012).

En particular, según Zoro y Castro (2016), entender las emociones de los líderes ayuda a comprender la cultura escolar y su alineamiento con los objetivos que se persiguen, las emociones de los docentes ante las decisiones del líder, la efectividad del manejo de las relaciones y la percepción del éxito del propio trabajo.

Respecto del manejo emocional y situacional, un liderazgo eficaz se asocia con la capacidad para tomar decisiones y resolver problemas emergentes (Leithwood, 2009). Es decir, la habilidad que tiene el líder para manejar incidentes que son la combinación de una situación inesperada con una falta de control emocional (Monereo, Weise y Álvarez, 2013). Un incidente es crítico cuando el impacto emocional es de tal intensidad que hace que el sujeto se sienta bloqueado o reaccione de forma extemporánea o inadecuada (negación, evitación, agresión, etc.). 
284 LAS EMOCIONES SURGIDAS ANTE UN INCIDENTE CRÍTICO EN EL ÁMBITO DEL LIDERAZGO EFICAZ: ESTUDIO COMPARATIVO ENTRE DIRECTIVOS NOVELES Y EXPERTOS - O. Nail, J. Valdivia, D. Rojas y C. Monereo

\section{Incidentes críticos}

Los incidentes críticos se caracterizan por ser situaciones imprevistas y acotadas en el tiempo (Everly \& Mitchell, 1997; Woods, 1997), que ponen en crisis a quien los sufre, desestabilizando la propia identidad profesional (Bilbao y Monereo, 2011), revelando las estructuras implícitas de actuación del sujeto (Tripp, 2011), superando sus mecanismos de defensa y autocontrol (Butterfield, Borgen, Amundson \& Maglio, 2005) e impactando en los planos cognitivo, social y emocional (Navarro Hinojosa, López Martínez y Barroso Flores, 1998).

Por tanto, cuando se desencadena un incidente crítico se movilizan procesos endógenos y exógenos que se traducen en un cambio en la identidad profesional del docente y, más específicamente, en una transformación de los elementos que conforman esa identidad (Bilbao y Monereo, 2011), tales como las emociones (Monereo y Badía, 2011; Sockman \& Sharma, 2008). En esta misma línea, Del Mastro y Monereo (2014) expresan que los eventos pueden clasificarse en función de dos criterios: si la situación es inesperada o no, es decir, si es frecuente o infrecuente; y si la situación afecta o no emocionalmente al docente o directivo, es decir, si está bajo su control o, por el contrario, escapa a este y genera conductas reactivas.

Se deben diferenciar los eventos de las rutinas, ya que estas últimas son situaciones habituales ante las cuales un docente responde con respuestas predeterminadas, lo cual le da una sensación de control y seguridad. Por su parte, los eventos son sorpresivos, pero no siempre provocan una desestabilización emocional. Los conflictos, en su forma rutinaria, pueden tener una presencia bastante continuada y esperada, se experimentan de manera negativa y conducen a una actitud de resignación por falta de recursos para afrontarlos.

Uno de los procedimientos para sistematizar y registrar la información de los incidentes críticos en educación corresponde a la técnica de análisis de incidentes críticos, que tiene por finalidad "recopilar observaciones directas del comportamiento humano, a fin de facilitar su uso en la solución de problemas prácticos" (Nail 
Kröyer, Gajardo Aguayo y Muñoz Reyes, 2012, p. 57). Esta técnica o procedimiento permite identificar las principales características de los sucesos que le acontecen al directivo, tales como su actuación profesional, las enseñanzas del caso, los tipos de emociones que surgen, como también reconocer a los actores que participan en el suceso. El objetivo de esta técnica es que sus pares asimilen y acomoden de manera constructiva este nuevo conocimiento con tal de perfeccionar la toma de decisiones ante sucesos semejantes (Gajardo, Ulloa y Nail, 2017).

Cabe agregar que la mirada cualitativa y experiencial que aporta el análisis de los incidentes críticos ayuda al directivo a movilizar sus capacidades, habilidades y actitudes emocionales para responder de manera óptima a un evento inesperado.

\section{La emoción}

Si bien la emoción es un componente esencial en el incidente crítico, no resulta sencillo conceptualizarlo, puesto que está representada por múltiples factores que se reflejan en respuestas fisiológicas, conductuales y subjetivas (Feldman y Blanco, 2006). En este sentido, Frijda (1993) sugiere que la emoción es un componente experiencial del afecto y es una apreciación subjetiva de un estado emocional.

Como proceso, la emoción se activa cuando el organismo detecta algún peligro, amenaza o desequilibrio, con el fin de poner en marcha los recursos a su alcance para controlar la situación (Fernández-Castro, 1999). Así mismo, Lazarus y Cohen-Charash (2001), como también Folkman y Lazarus (1980), coinciden en afirmar que las emociones son procesos adaptativos cuyo efecto positivo o negativo dependerá de la valoración o significado que tenga la situación y de los recursos que tiene la persona para adaptarse a ella. En este contexto la Tabla 1 muestra una clasificación psicopedagógica de las emociones según Bisquerra (2009). 
286 LAS EMOCIONES SURGIDAS ANTE UN INCIDENTE CRÍTICO EN EL ÁMBITO DEL LIDERAZGO EFICAZ: ESTUDIO COMPARATIVO ENTRE DIRECTIVOS NOVELES Y EXPERTOS - O. Nail, J. Valdivia, D. Rojas y C. Monereo

Tabla 1

Clasificación de las emociones

\begin{tabular}{|c|c|}
\hline \multicolumn{2}{|r|}{ Emociones negativas } \\
\hline Miedo & Temor, horror, pánico, terror, pavor, desasosiego, susto, fobia. \\
\hline Ira & $\begin{array}{l}\text { Rabia, cólera, rencor, odio, furia, indignación, resentimiento, aversión, } \\
\text { exasperación, tensión, excitación, agitación, acritud, animadversión. }\end{array}$ \\
\hline Tristeza & $\begin{array}{l}\text { Depresión, frustración, decepción, aflicción, pena, dolor, pesar, desconsuelo, } \\
\text { pesimismo, melancolía, soledad. }\end{array}$ \\
\hline Asco & Aversión, repugnancia, rechazo, desprecio. \\
\hline Ansiedad & Angustia, desesperación, inquietud, estrés, preocupación, anhelo, desazón. \\
\hline \multicolumn{2}{|r|}{ Emociones sociales } \\
\hline Vergüenza & $\begin{array}{l}\text { Culpabilidad, timidez, vergüenza ajena, bochorno, pudor, recato, rubor, } \\
\text { sonrojo, verecundia. }\end{array}$ \\
\hline \multicolumn{2}{|r|}{ Emociones positivas } \\
\hline Alegría & $\begin{array}{l}\text { Entusiasmo, euforia, excitación, contento, deleite, diversión, placer, } \\
\text { gratificación. }\end{array}$ \\
\hline Amor & $\begin{array}{l}\text { Aceptación, afecto, cariño, ternura, simpatía, interés, cordialidad, confianza, } \\
\text { amabilidad, afinidad, respeto, devoción, adoración. }\end{array}$ \\
\hline Felicidad & $\begin{array}{l}\text { Bienestar, gozo, tranquilidad, paz interior, dicha, placidez, satisfacción, } \\
\text { serenidad. }\end{array}$ \\
\hline \multicolumn{2}{|r|}{ Emociones ambiguas } \\
\hline Sorpresa & $\begin{array}{l}\text { Puede ser positiva o negativa. En esta familia se pueden incluir: sobresalto, } \\
\text { asombro, desconcierto, confusión, perplejidad, admiración, inquietud, } \\
\text { impaciencia. Relacionadas con la sorpresa, pero en el otro extremo de la } \\
\text { polaridad pueden estar la anticipación y expectativa, que pretenden prevenir } \\
\text { sorpresas. }\end{array}$ \\
\hline
\end{tabular}

Fuente: Bisquerra, p. 92, 2009.

\section{Directivos noveles y expertos}

En las investigaciones de Leithwood y Stager (1989) se explicitan marcadas diferencias entre las personas expertas y las novatas. En comparación con las novatas, los expertos son más capaces de regular sus propios procesos para resolver problemas mediante un mayor control metacognitivo, es decir, reflexionan en acción y acerca de la acción (Berliner, 1986). Además, disponen de más información relevante acerca del problema (Berliner, 1986; Norris, 1985), representan los problemas utilizando categorías más abstractas (Adelson, 1984), hacen referencia a principios más básicos (Berliner, 1986; Chi, Feltovich \& Glaser, 1981; Voss, Greene, Post \& Penner, 1983) y tienen mayores destrezas para detectar patrones en forma más rápida (Bereiter \& Scardamalia, 1986; Berliner, 1986). Por 
ello, los expertos invierten más tiempo planificando sus estrategias globales iniciales y son también más flexibles y oportunos durante el proceso de solución de un problema.

En el marco educacional, Leithwood y Stager (1989) revelan las notorias diferencias entre los directivos expertos y novatos respecto de la respuesta manifiesta ante el surgimiento de un problema poco estructurado en el contexto escolar, las cuales se pueden observar en la Tabla 2.

Tabla 2

Estrategias diferenciadoras para la solución de un problema desde la mirada de un directivo novel y experto

\begin{tabular}{|c|c|c|c|}
\hline & Componente & Experto & Novel \\
\hline \multirow{4}{*}{ 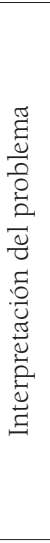 } & $\begin{array}{l}\text { a. Fundamento } \\
\text { para asignarle } \\
\text { prioridad. }\end{array}$ & $\begin{array}{l}\text { Consecuencias para la escuela } \\
\text { y para el desarrollo académico } \\
\text { de muchos alumnos. }\end{array}$ & $\begin{array}{l}\text { Más preocupado de las } \\
\text { consecuencias para sí mismo. }\end{array}$ \\
\hline & $\begin{array}{l}\text { b. Dificultad } \\
\text { percibida. }\end{array}$ & $\begin{array}{l}\text { Los problemas difíciles son } \\
\text { manejables mediante una } \\
\text { cuidadosa reflexión. }\end{array}$ & $\begin{array}{l}\text { Los problemas difíciles } \\
\text { generan miedo y estrés. }\end{array}$ \\
\hline & $\begin{array}{l}\text { c. Formas de } \\
\text { comprender. }\end{array}$ & $\begin{array}{l}\text { Recoge información. } \\
\text { Proporciona un a } \\
\text { interpretación clara y global } \\
\text { de los problemas. }\end{array}$ & $\begin{array}{l}\text { Elabora supuestos en vez } \\
\text { de recoger información. Los } \\
\text { temas irrelevantes tienden a } \\
\text { nublar la interpretación. }\end{array}$ \\
\hline & $\begin{array}{l}\text { d. Uso de } \\
\text { experiencias. }\end{array}$ & $\begin{array}{l}\text { Directamente relevantes en el } \\
\text { problema. }\end{array}$ & $\begin{array}{l}\text { Tiende a recordar las } \\
\text { experiencias difíciles más que } \\
\text { las exitosas. }\end{array}$ \\
\hline \multicolumn{3}{|c|}{$\begin{array}{l}\text { Objetivos de solución Pre ocupado por las } \\
\text { de problemas. } \\
\text { implicancias para los alumnos } \\
\text { y la calidad del programa, } \\
\text { por entregar conocimiento } \\
\text { a los apoderados y por el } \\
\text { conocimiento. }\end{array}$} & $\begin{array}{l}\text { Menciona con mayor } \\
\text { frecuencia los objetivos } \\
\text { relacionados con el equipo } \\
\text { educativo. Está preocupado } \\
\text { de que los apoderados estén } \\
\text { felices y por los sentimientos. }\end{array}$ \\
\hline \multicolumn{3}{|c|}{ Principios. } & No los menciona. \\
\hline \multicolumn{3}{|c|}{$\begin{array}{ll}\text { Obstáculos. } & \text { Menciona pocos obstáculos o } \\
& \text { ninguno y encuentra la forma } \\
& \text { de lidiar con ellos. }\end{array}$} & $\begin{array}{l}\text { Menciona más los obstáculos } \\
\text { y estos constituyen grandes } \\
\text { barreras. }\end{array}$ \\
\hline
\end{tabular}

Fuente: Leithwood y Stager, p. 150, 1989. 
Según lo expuesto y producto de la ausencia de sistematización del conocimiento respecto de las manifestaciones de la emocionalidad en directivos noveles y expertos, la presente investigación buscó describir con un enfoque socioconstructivo los principales alcances de las percepciones y emocionalidad de los directivos chilenos de las provincias de Concepción y Nuble, Región del Biobío, ante el surgimiento de un incidente crítico desde la mirada de la narración, la actuación y el manejo de situaciones disruptivas de carácter socioeducativas.

\section{Objetivos}

Considerando lo presentado, a través de esta investigación se buscó analizar cuáles eran las emociones que se manifestaban en un directivo cuando surgía un incidente crítico en la organización educativa, analizando y contextualizando con ello sus experiencias como líderes escolares. Por lo tanto, se desea generar conocimiento sustentado en el desarrollo emocional "positivo" y "negativo" de los directivos que permita ser un aporte a sus pares ante el surgimiento de un suceso inesperado. De esta forma, los objetivos de la presente investigación fueron los siguientes:

- Analizar las emociones surgidas en un directivo novel y experto a partir de un incidente crítico, de tal manera que las acciones evidenciadas permitan dilucidar los distintos mecanismos de resolución o respuesta del directivo ante un evento inesperado.

- Explicar las respuestas emocionales de un directivo ante un evento imprevisto ocurrido en la organización escolar, con la finalidad de reconocer no solo las causas y barreras que impiden su solución, sino que también las estrategias y aprendizajes obtenidos de la participación del directivo novel y experto.

- Registrar y describir a través de la una bitácora en línea los diferentes tipos de emociones que se manifiestan en el directivo novel y experto en un centro escolar ante el surgimiento de un incidente crítico. 


\section{Método}

El diseño de investigación se basó en un estudio de casos, el que implica un proceso de indagación caracterizado por el examen detallado, comprehensivo, sistemático y en profundidad del caso de objeto de interés (García-Jiménez, 1991). La recogida de datos se realizó a través de técnicas de investigación social: por un lado, se recurrió a los grupos focales, que es "una técnica que privilegia el habla, y cuyo interés consiste en captar la forma de pensar, sentir y vivir de los individuos que conforman el grupo" (Hamui-Sutton y Varela-Ruiz, 2013, p. 57), y por otro, a través de una bitácora de incidentes críticos en línea, la cual contenía en una de sus secciones la pauta de análisis de los incidentes críticos, definida de acuerdo con los planteamientos de Nail Kröyer et al. (2012), en la que se ha incorporado los componentes emocionales basados en la clasificación de Bisquerra (2009).

Por consiguiente, la metodología utilizada corresponde a una investigación cualitativa de carácter exploratoria-descriptiva, cuyo objetivo es la comprensión centrada en la indagación en los hechos (Stake, 1995). Así, a través de la comparación, se desea revelar la actuación emocional de los directivos noveles y expertos ante el surgimiento de un incidente crítico.

\subsection{Muestra}

La investigación se focalizó en establecimientos educacionales públicos de la Región del Biobío, Chile, los cuales están bajo administración municipal, contemplando una población de 354 directivos que desempeñan sus funciones en las provincias de Concepción y Ñuble.

La muestra fue no probabilística de tipo causal o incidental cuyo procedimiento de selección contempló la elección de individuos a los que se tuviera fácil acceso. Así, la muestra consistió en 29 directivos de los cuales se obtuvieron 42 registros de incidentes críticos. Las muestras fueron agrupadas en directivos noveles y expertos según la visión de la Asociación Nacional de Directivos Escolares de Chile (Andech, 2018), la cual explicita que la figura del 
directivo novel está en un rango entre 1 a 5 años de su "trayectoria profesional, conocimientos técnicos y experiencia en el cargo". Por otro lado, la misma institución circunscribe al directivo experto como aquel que tiene 10 años o más de trayectoria profesional, lo que es coincidente con lo consignado en la Tabla 3.

Asimismo, y en relación con los diversos estudios realizados (Gabarro, 1987; Weindling, 1999) cabe mencionar que no existe un consenso respecto de la duración de la etapa de directivo novel. Los autores aquí consignados definen una serie de fases que experimentan los directivos noveles en cuanto a su cargo en la organización escolar.

Tabla 3

Etapas experimentadas por los nuevos directores en el cargo

\begin{tabular}{ll}
\hline \multicolumn{1}{c}{ Gabarro (1987) } & \multicolumn{1}{c}{ Weindling (1999) } \\
\hline 1. Tomar las riendas (primeros seis & 1. Entrada y encuentro (primeros meses). \\
meses). & 2. Hacerse cargo (3-12 meses). \\
2. Inmersión (6-12 meses). & 3. Reacomodo (segundo año). \\
3. Rediseño (12-21 meses). & 4. Refinamiento (4-5 años). \\
4. Consolidación (21-27 meses). & 5. Consolidación (5-7 años). \\
5. Refinamiento (27-36 meses). & 6. Cima (a partir de los 8 años). \\
\hline
\end{tabular}

Fuente: García-Garduño, Slater y López-Gorosave, p. 43, 2011.

No obstante, para esta investigación el aporte de Andech (2018) es un buen punto de referencia, más aún si se considera que su propuesta se sustenta en el desarrollo profesional del directivo, aspecto que también es parte constitutiva de las etapas anteriores mencionadas en la Tabla 3.

Tabla 4

Definición del tipo de directivo conforme a la antigüedad en el cargo en el contexto de la investigación

\begin{tabular}{cc}
\hline Tipo de directivo & Antigüedad en el cargo \\
\hline Novel & Entre 1 a 5 años \\
\hline Experto & Sobre 5 años \\
\hline
\end{tabular}

Fuente: Elaboración propia.

Cabe destacar que el 100\% de la muestra estuvo conformada por directivos de los establecimientos participantes (directores, subdirectores, jefes de la Unidad Técnico Pedagógica, inspectores 
generales), lo cual es relevante por la focalización de la investigación, lo que se complementa con su experiencia profesional y el género respectivo, tal como se muestra en la Tabla 5.

Tabla 5

Características de la muestra para las provincias de Concepción y Nuble 2017

\begin{tabular}{lcccc}
\hline & \multicolumn{2}{c}{ Categoría } & \multicolumn{2}{c}{ Género } \\
\hline & Novel & Experto & Masculino & Femenino \\
\hline Provincia & & & & \\
\hline Concepción & $5(38 \%)$ & $8(62 \%)$ & $6(46 \%)$ & $7(54 \%)$ \\
\hline Nuble & $5(31 \%)$ & $11(69 \%)$ & $7(44 \%)$ & $9(56 \%)$ \\
\hline Total & $10(34 \%)$ & $19(66 \%)$ & $13(45 \%)$ & $16(55 \%)$ \\
\hline
\end{tabular}

Fuente: Elaboración propia.

Cabe hacer notar que la experiencia profesional de los directivos noveles era de 3,5 años en promedio, a diferencia de los directivos expertos, quienes tenían 13 años de experiencia en promedio en los diversos establecimientos en los que habían ejercido dicho cargo.

\subsection{Recopilación de información}

En primera instancia se realizaron grupos focales que tuvieron por finalidad extraer información cualitativa de los incidentes críticos más desestabilizadores que les habían ocurrido a los directivos noveles y expertos, así como también en cuanto a las estrategias que utilizaron para afrontarlos. De este modo, para registrar y evidenciar el comportamiento de los directivos noveles y expertos ante un incidente crítico, se plantearon cuestiones que tenían relación con su desarrollo profesional, y la manera en que habían enfrentado y solucionado estas situaciones emergentes en el ámbito educacional. Para ello, se conformaron grupos de expertos y noveles por separado, como una manera de recabar información acerca de la forma de enfrentar el surgimiento de un incidente crítico en donde la emocionalidad y las estrategias de solución son aspectos decidores de la experiencia profesional que tienen en el establecimiento escolar.

La Tabla 6 resume las fechas y la participación de los grupos focales realizados. 
292 LAS EMOCIONES SURGIDAS ANTE UN INCIDENTE CRÍTICO EN EL ÁMBITO DEL LIDERAZGO EFICAZ: ESTUDIO COMPARATIVO ENTRE DIRECTIVOS NOVELES Y EXPERTOS - O. Nail, J. Valdivia, D. Rojas y C. Monereo

Tabla 6

Participación de directivos en los grupos focales 2017

\begin{tabular}{lll}
\hline & Grupo focal 1 & Grupo focal 2 \\
\hline Ciudad & 29 junio 2017 & 19 octubre 2017 \\
\hline Concepción & Noveles $=4$ & \\
\cline { 2 - 3 } & Expertos $=7$ & Noveles $=3$ \\
\cline { 3 - 3 } Chillán & & Expertos $=7$ \\
\hline
\end{tabular}

Fuente: Elaboración propia.

Complementariamente, se utilizó una bitácora de incidentes críticos desarrollada en línea ${ }^{5}$, correspondiente a una encuesta validada por jueces expertos en relación con su contenido y relevancia para la investigación desde el punto de vista de sus objetivos y aportaciones. Esta bitácora consideró tres dimensiones fundamentales:

a) Antecedentes profesionales: información personal del directivo (edad y género) y la antigüedad en que asumió un cargo directivo en un centro educativo (directivo novel y experto), entre otros aspectos.

b) Antecedentes del incidente crítico: se utilizó la técnica de análisis de incidentes críticos de Nail Kröyer et al. (2012), la que está conformada por las siguientes secciones:

- Presentación del caso: se describe la situación de la manera más objetiva posible.

- Emociones despertadas: se citan aquellas emociones que se presentan en el momento en que se enfrentó el incidente crítico.

- Actuación profesional: es el relato de la actuación del profesor en el manejo del incidente crítico, específicamente, lo que hizo y también lo que no hizo conductualmente.

- Resultados de esta actuación: se describe el hecho y los efectos que tuvo la acción profesional.

- Dilema: entendido como el planteamiento de las problemáticas suscitadas a partir del hecho.

5 Disponible en directivosic.blogspot.com/ 
- Enseñanzas del caso: se desea dar respuestas a cuestiones como: ¿Qué aprendí de esta situación? ¿Qué aprendieron los demás?

c) Antecedentes de las emociones surgidas en el incidente crítico: se consideraron las aportaciones de Bisquerra (2009) para que, a través de selección múltiple, los directivos pudieran indicar el tipo de emoción e intensidad involucradas en el incidente.

\subsection{Método de análisis}

Los grupos focales fueron registrados en audio y luego transcritos, separadamente según si se trataba de directores noveles o expertos. Luego de ello se realizó un proceso de codificación abierta de la transcripción, seguida de una codificación axial mediante el principio de comparación constante de la teoría fundamentada (Corbin \& Strauss, 1990), manteniendo el eje axial novel-experto para facilitar el análisis comparativo. En este proceso, el criterio para considerar saturada una categoría emergente consistió en contabilizar un mínimo de seis o más fundamentos que aportaran a la categoría. Así, la transcripción fue codificada abiertamente y por cada código se crearon familias de códigos que correspondían a las categorías emergentes ${ }^{6}$.

Respecto de la bitácora en línea, se llevaron a cabo análisis estadístico-descriptivos para sintetizar la información. Para analizar la relación entre las variables encuestadas, se realizaron múltiples análisis para determinar diferencias de grupos (prueba no paramétrica U de Mann-Whitney). Los resultados presentados a continuación solo hacen referencia a las pruebas que evidenciaron aquellos estadísticamente significativos y que cumplían con los supuestos necesarios para la aplicación de tales pruebas. En adición, la bitácora de incidentes críticos fue analizada mediante una codificación abierta y selectiva para obtener categorías inductivas, de igual forma que el análisis de los grupos focales.

6 Los fundamentos de cada categoría emergente se contabilizan en la Tabla 8. 
294 LAS EMOCIONES SURGIDAS ANTE UN INCIDENTE CRÍTICO EN EL ÁMBITO DEL LIDERAZGO EFICAZ: ESTUDIO COMPARATIVO ENTRE DIRECTIVOS NOVELES Y EXPERTOS - O. Nail, J. Valdivia, D. Rojas y C. Monereo

\section{Resultados}

\subsection{Análisis descriptivo de la bitácora en línea}

En la Figura 1 se observa que la mayor cantidad de incidentes registrados fueron reportados por directivos que tenían entre $50 \mathrm{y}$ 65 años, mientras que el segundo grupo más grande se ubicó entre los 38 y los 49 años.

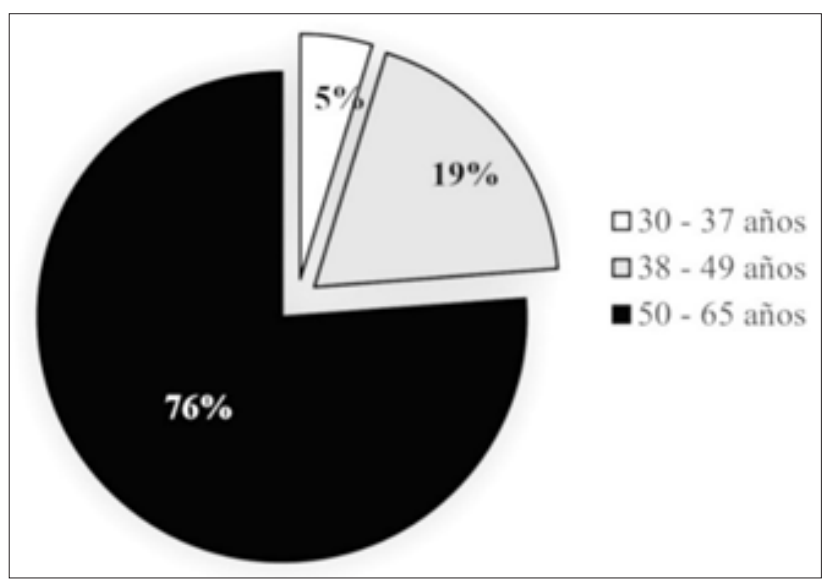

Figura 1. Rango de edad de directivos que reportaron incidentes. Fuente: Elaboración propia.

Los participantes de esta investigación que ejercían un rol de directivo anterior al año 2011 (experto) correspondieron al $71,5 \%$, mientras que el 28,5\% ejercía como directivo desde 2013 o posteriormente (noveles).

Como se observa en la Figura 2, los principales actores involucrados en los incidentes críticos correspondieron a profesores, alumnos, apoderados y directivos. 


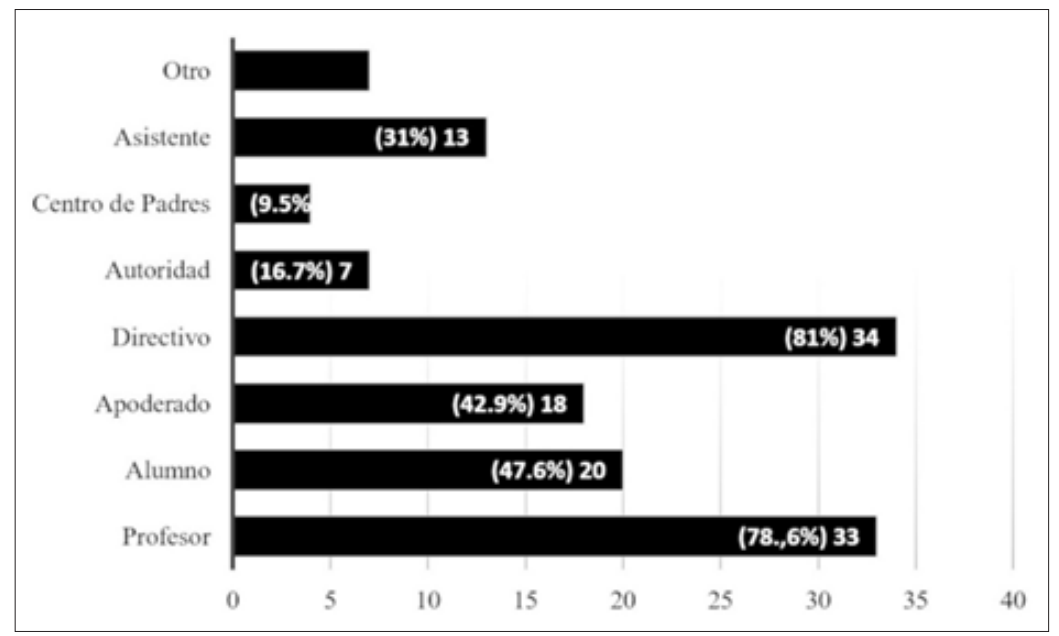

Figura 2. Frecuencia y porcentaje de actores involucrados en incidente crítico. Fuente: Elaboración propia.

Respecto de las emociones surgidas, la Figura 3 muestra que más del $71 \%$ de estas fueron negativas y el 23,8\% fueron mixtas (ambas), lo que es esperable debido a la naturaleza de los eventos registrados (incidentes críticos). Además, la Figura 4 muestra que más del 80\% de los incidentes tuvo un efecto en el desempeño laboral con una intensidad catalogada de "bastante" o "mucho".

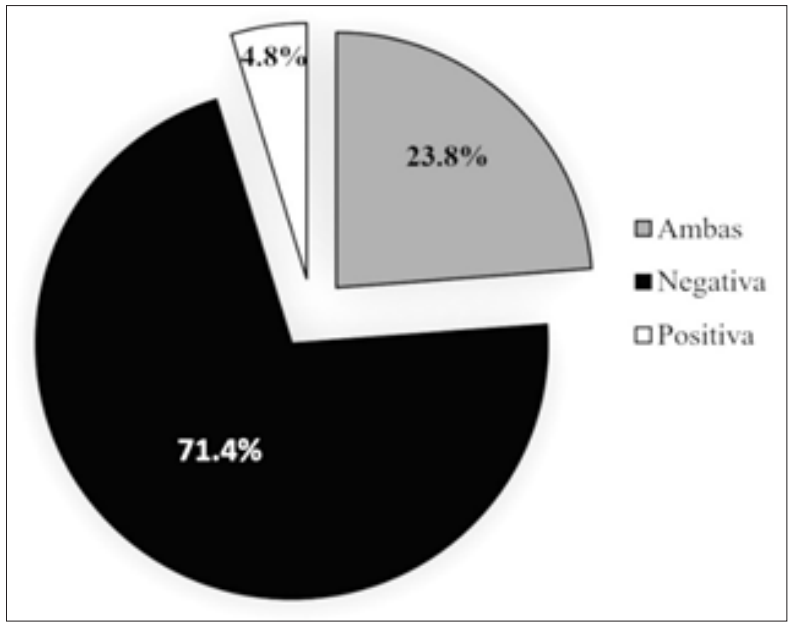

Figura 3. Total de emociones surgidas ante un incidente crítico.

Fuente: Elaboración propia. 

LIDERAZGO EFICAZ: ESTUDIO COMPARATIVO ENTRE DIRECTIVOS NOVELES Y EXPERTOS - O. Nail, J. Valdivia, D. Rojas y C. Monereo

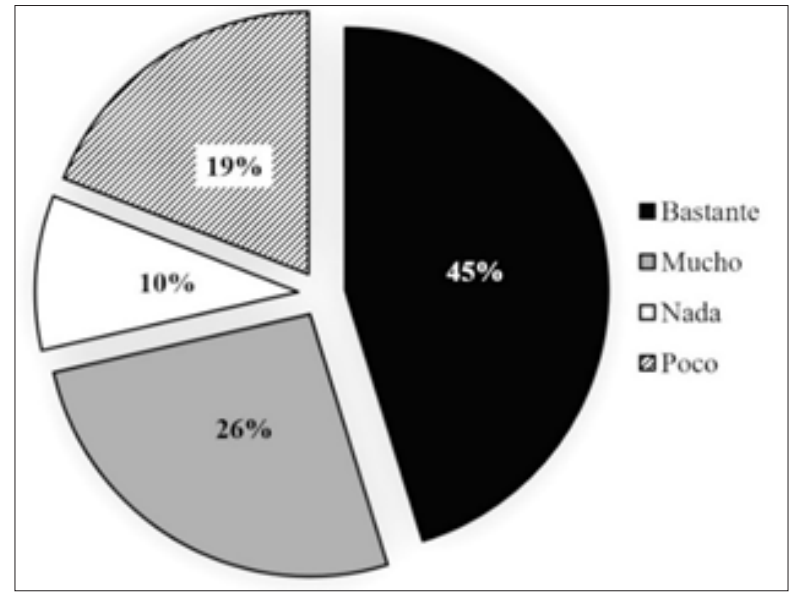

Figura 4. Intensidad del efecto en el desempeño laboral ante un incidente crítico. Fuente: Elaboración propia.

Las Figuras 5 y 6, en tanto, muestran los porcentajes de las dos emociones con mayor recuento en la bitácora: rabia y tristeza, respectivamente.

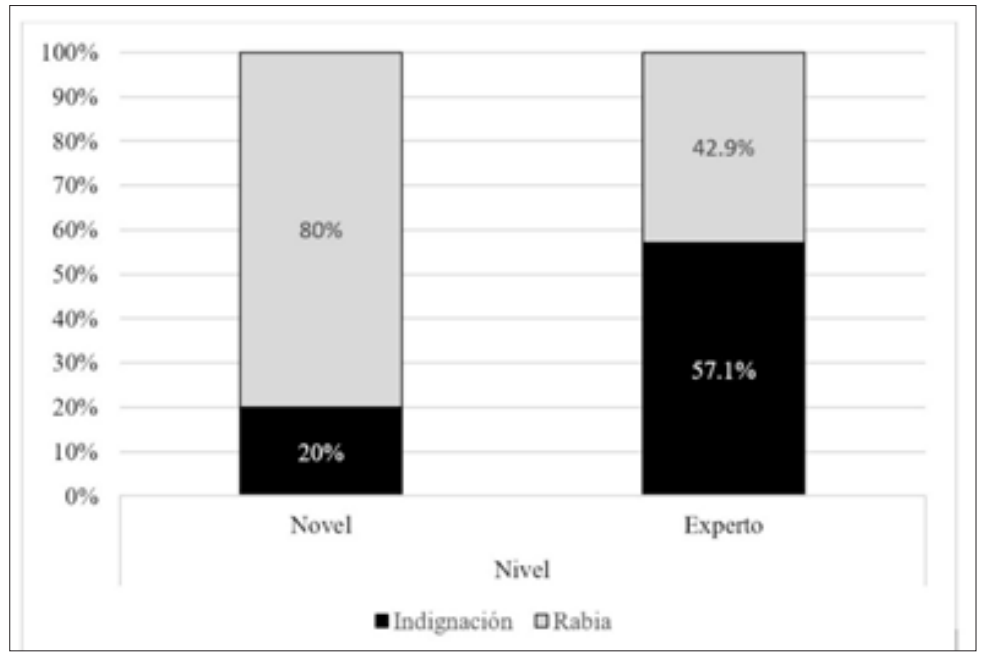

Figura 5. Gráfico de la rabia según nivel de directivo.

Fuente: Elaboración propia. 


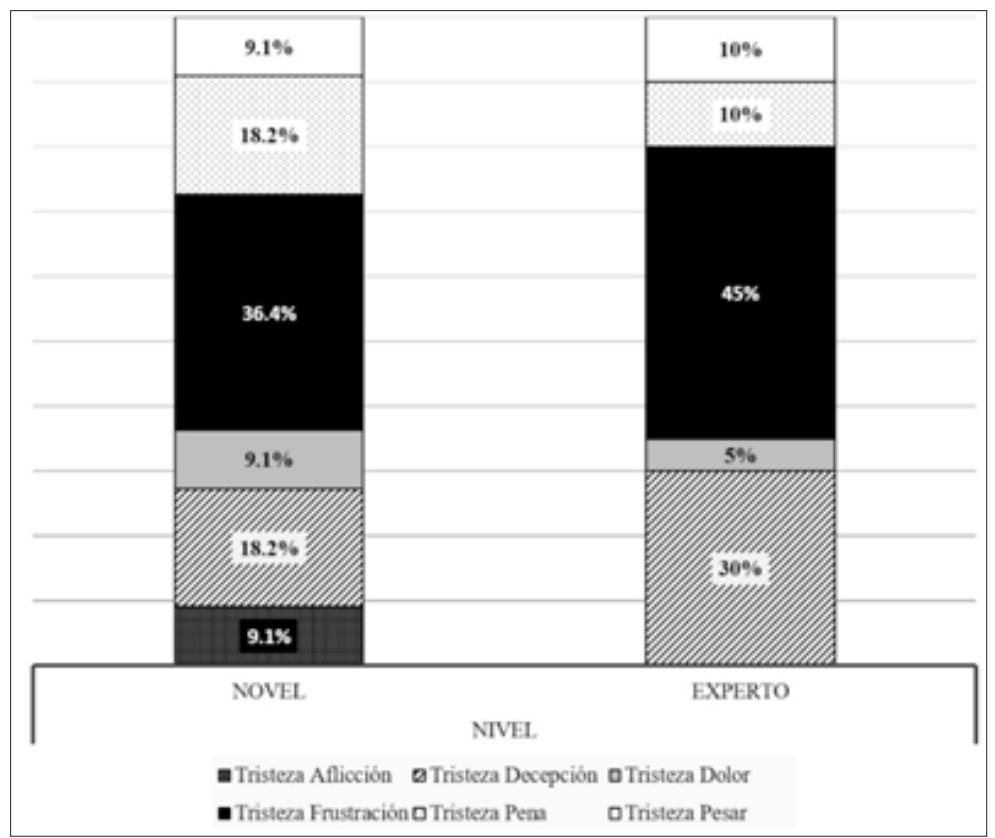

Figura 6. Gráfico de la tristeza según nivel directivo. Fuente: Elaboración propia.

Por su parte, la relación entre la cantidad de años en cargos directivos y el efecto del incidente crítico en su desempeño laboral se muestra en la Figura 7. Como se aprecia, a los directivos noveles les afecta "mucho" y "bastante" en mayor proporción que a los directivos expertos, aunque a estos últimos les afecta "poco" en mayor proporción los incidentes reportados. 


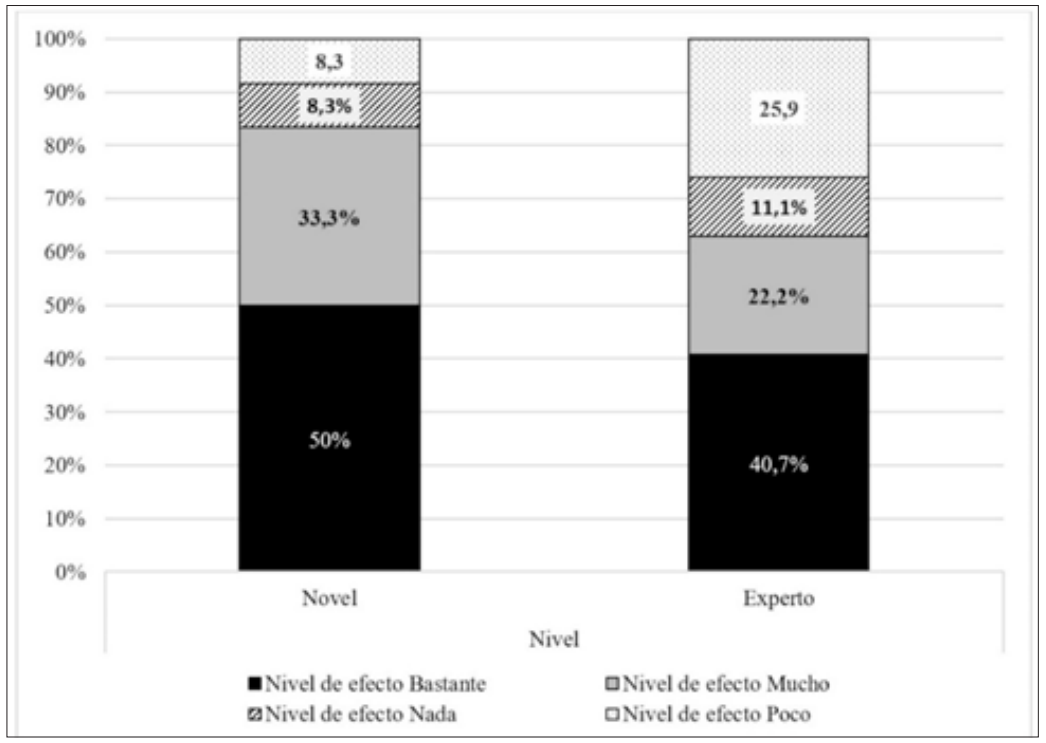

Figura 7. Valoración acerca de cuánto afectó al directivo (novel y experto) el incidente crítico en su desempeño profesional.

Fuente: Elaboración propia.

En lo referente a los tipos de emociones despertadas, la Figura 8 presenta los niveles de efecto en el desempeño laboral según el tipo de emoción producida por el incidente crítico. Como se observa, a medida que la emoción se hace más negativa, el efecto en el desempeño laboral es mayor. 


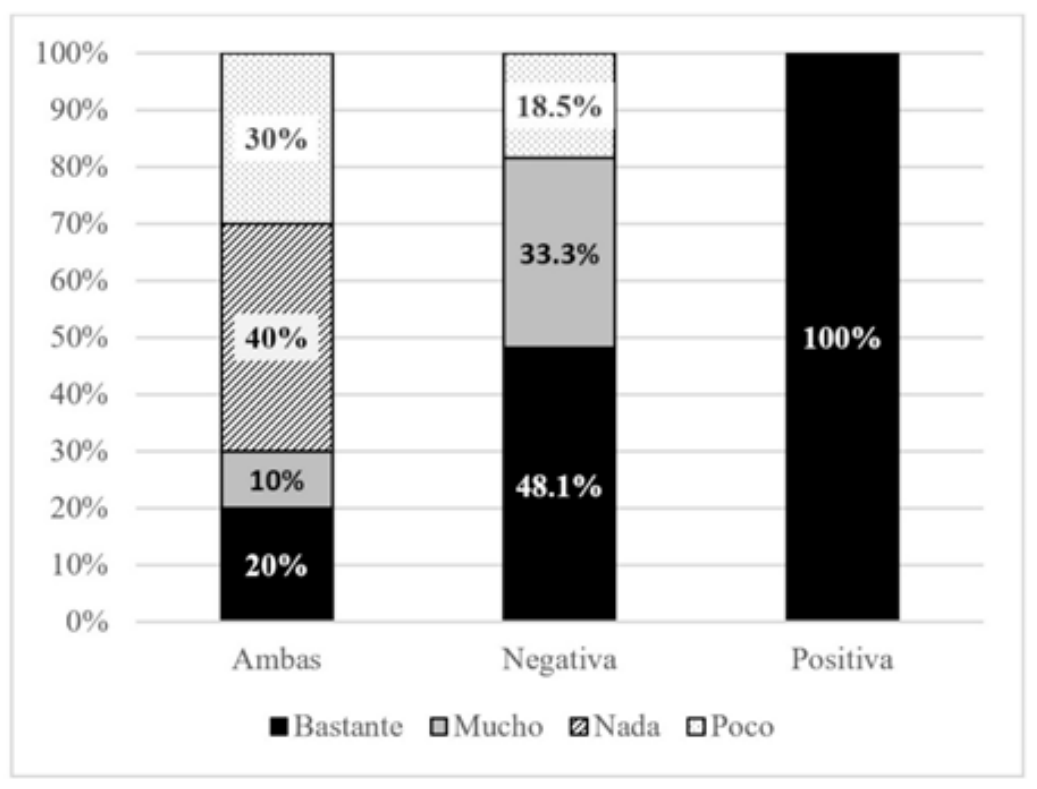

Figura 8. Nivel de efecto en el desempeño profesional del incidente crítico según el principal tipo de emoción despertada.

Fuente: Elaboración propia.

Así mismo, las pruebas estadísticas realizadas mostraron diferencias significativas en el efecto del desempeño laboral entre los incidentes críticos que despertaron "ambas" emociones (positivas y negativas) y los incidentes que despertaron emociones "negativas" $(Z$ $=-2.950, p<0,05)$.

En cuanto al análisis cualitativo, la Tabla 7 muestra en forma comparativa las categorías inductivas obtenidas de la bitácora en línea, mientras que la Tabla 8 hace lo propio con las categorías emergentes de los grupos focales. 
Tabla 7

Análisis comparativo de las apreciaciones de los directivos en relación con los incidentes críticos

\begin{tabular}{|c|c|c|c|c|}
\hline Categoría & Subcategoría & Descripción & Directivo novel & Directivo experto \\
\hline \multirow[t]{6}{*}{ Causas. } & $\begin{array}{l}\text { Acerca de la } \\
\text { autoridad. }\end{array}$ & $\begin{array}{l}\text { C a u s a s } \\
\text { relacionadas } \\
\text { con la imagen } \\
\text { de autoridad del } \\
\text { director. }\end{array}$ & $\begin{array}{l}\text { Porque otra } \\
\text { persona sobrepasa } \\
\text { su autoridad. }\end{array}$ & No evidenciado. \\
\hline & Conflicto. & $\begin{array}{l}\text { Conflicto entre } \\
\text { docentes o } \\
\text { apoderados. }\end{array}$ & $\begin{array}{l}\text { Referencias a } \\
\text { conflictos laborales } \\
\text { y con apoderados } \\
\text { conflictivos. }\end{array}$ & $\begin{array}{l}\text { Referencias a los } \\
\text { conflictos como } \\
\text { asuntos de clima } \\
\text { laboral. }\end{array}$ \\
\hline & Descompensación. & $\begin{array}{l}\text { Estudiante } \\
\text { se hace } \\
\text { incontrolable }\end{array}$ & $\begin{array}{l}\text { Descompensación } \\
\text { de estudiante, } \\
\text { pérdida de control. }\end{array}$ & No evidenciado. \\
\hline & & $\begin{array}{l}\text { s e } \\
\text { descompensa). }\end{array}$ & & \\
\hline & Violencia. & $\begin{array}{l}\text { Cualquier } \\
\text { episodio de } \\
\text { violencia. }\end{array}$ & $\begin{array}{l}\text { Violencia entre } \\
\text { alumnos. }\end{array}$ & $\begin{array}{l}\text { Violencia entre } \\
\text { alumnos, violencia } \\
\text { profesor-alumno. }\end{array}$ \\
\hline & Personificación. & $\begin{array}{l}\text { Personifica la } \\
\text { causa. }\end{array}$ & $\begin{array}{l}\text { Mayor juicio hacia } \\
\text { docentes y crianza } \\
\text { de los alumnos. }\end{array}$ & No evidenciado. \\
\hline \multirow[t]{2}{*}{$\begin{array}{l}\text { Relación } \\
\text { con las } \\
\text { emociones. }\end{array}$} & Imagen. & $\begin{array}{l}\text { Emociones } \\
\text { s u r g i d a s } \\
\text { respecto de su } \\
\text { propia imagen } \\
\text { o del colegio. }\end{array}$ & $\begin{array}{l}\text { Miedo a las } \\
\text { consecuencias } \\
\text { externas, a la } \\
\text { autoridad o la } \\
\text { propia imagen ante } \\
\text { apoderados. }\end{array}$ & $\begin{array}{l}\text { Impotencia por } \\
\text { no poder manejar } \\
\text { ciertas situaciones. } \\
\text { Preocupación (en } \\
\text { menor medida) } \\
\text { por no perder su } \\
\text { autoridad. }\end{array}$ \\
\hline & Otras. & $\begin{array}{l}\mathrm{O} \text { t } \mathrm{r} \text { a s } \\
\text { emociones. }\end{array}$ & $\begin{array}{l}\text { Pena por las } \\
\text { situaciones } \\
\text { ocurridas. }\end{array}$ & No evidenciado. \\
\hline \multirow[t]{2}{*}{ Aprendizajes. } & Emociones. & $\begin{array}{l}\text { Cualquier } \\
\text { a s p e t o } \\
\text { a prendido } \\
\text { acerca de } \\
\text { sus propias } \\
\text { emociones. }\end{array}$ & $\begin{array}{l}\text { Aprende a } \\
\text { controlar sus } \\
\text { emociones. }\end{array}$ & $\begin{array}{l}\text { Aprende a } \\
\text { controlar sus } \\
\text { emociones y es } \\
\text { más consciente de } \\
\text { la dificultad de su } \\
\text { trabajo. }\end{array}$ \\
\hline & Procedimiento. & $\begin{array}{l}\text { Cualquier } \\
\text { a s p e t o } \\
\text { procedimental } \\
\text { que ayuda } \\
\text { a afrontar el } \\
\text { problema. }\end{array}$ & $\begin{array}{l}\text { Aprende a tratar } \\
\text { con autoridades y } \\
\text { apoderados. }\end{array}$ & $\begin{array}{l}\text { Aprende a tratar } \\
\text { con otros y } \\
\text { monitorear a los } \\
\text { subordinados. } \\
\text { En general, hay } \\
\text { aprendizajes más } \\
\text { sistematizados. }\end{array}$ \\
\hline
\end{tabular}

Fuente: Elaboración propia. 


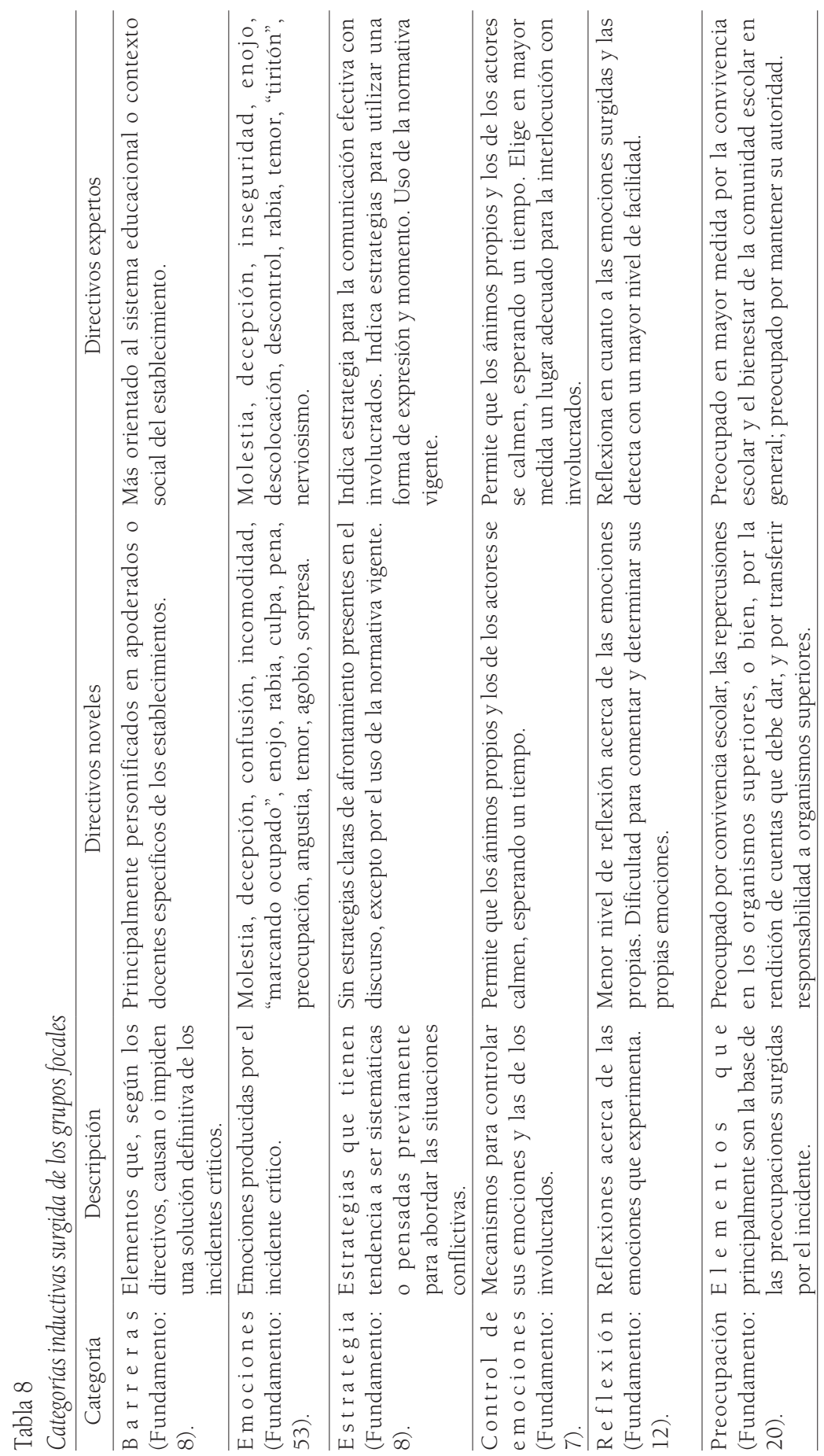


302 LAS EMOCIONES SURGIDAS ANTE UN INCIDENTE CRÍTICO EN EL ÁMBITO DEL LIDERAZGO EFICAZ: ESTUDIO COMPARATIVO ENTRE DIRECTIVOS NOVELES Y EXPERTOS - O. Nail, J. Valdivia, D. Rojas y C. Monereo

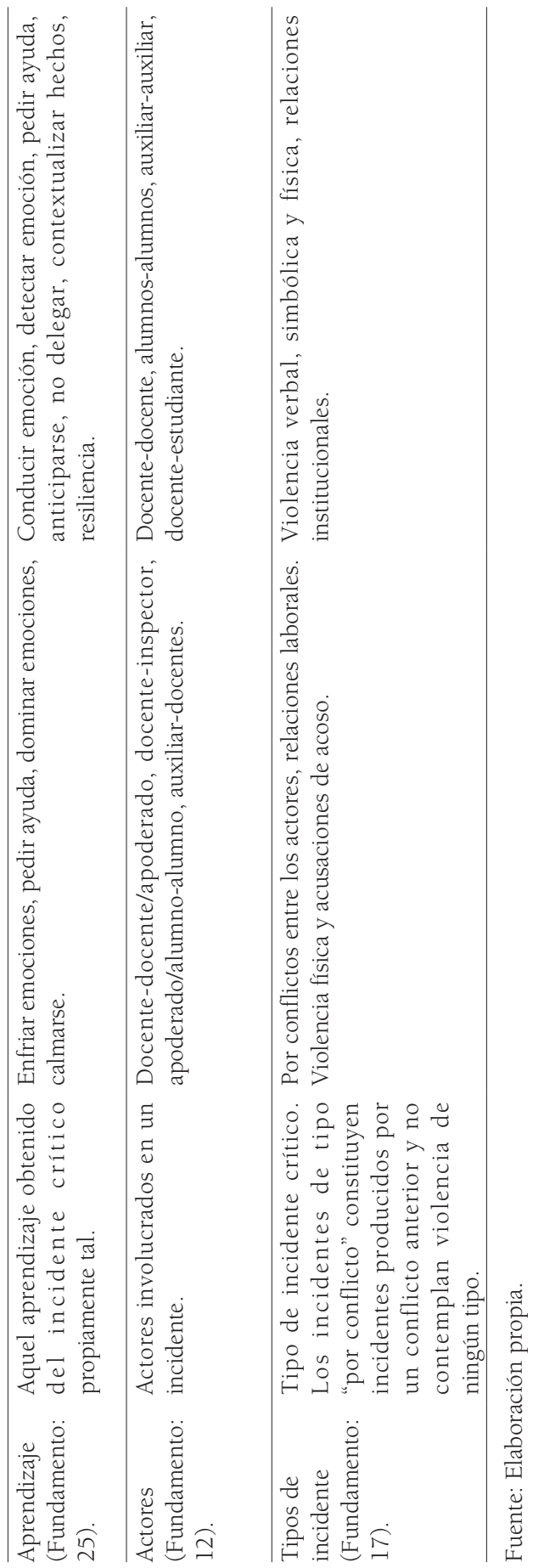




\section{Análisis y discusión}

En primera instancia, se pudo evidenciar que el $75 \%$ de los directivos tiene más de 50 años y un 66\% corresponde a directivos expertos. En cuanto a los incidentes críticos reportados, en su mayoría los directivos describieron que se trataba de eventos protagonizados por directivos, profesores, alumnos y apoderados.

Según la clasificación general del tipo de emociones aportada por Bisquerra (2009), las emociones negativas fueron las mayormente reportadas con un $71,4 \%$, seguidas de las emociones positivas con un $23,8 \%$ de los casos. Esto concuerda con lo descrito por Del Mastro y Monereo (2014), ya que los incidentes críticos son preferentemente asociados con emociones negativas, producto de lo inesperado de la situación y el control emocional inadecuado producido por la intensidad con que estos se manifiestan. En relación con ello, el efecto percibido de los incidentes críticos sobre el desempeño laboral obtuvo una valoración "bastante" en un 45\% de las ocasiones y un 26\% lo evaluó como "mucho", lo que puede revelar que la intensidad del efecto que tiene un incidente en el quehacer profesional (no solo personal) puede ser un factor determinante para percibirlo como crítico.

Respecto de las emociones que despertaron los incidentes, las más frecuentes fueron la rabia y la tristeza, observándose una diferencia entre directivos de nivel novel y experto. Los primeros reportaron un $80 \%$ de los casos con emoción de rabia, mientras que los expertos solo reportaron un $42,9 \%$ de este tipo de emociones. Esto se condice con lo obtenido en el análisis cualitativo de la bitácora en línea, donde se observó que los directivos noveles sienten más rabia debido a las consecuencias que estos incidentes pueden ocasionar, los que en su mayoría corresponden a vislumbran amenazada su estabilidad laboral y su imagen de autoridad ante sus subalternos, o bien, ante las instituciones fiscalizadoras del Estado, por lo que se preocupan en mayor medida por las situaciones que les afectan a sí mismos y no a su comunidad.

En otras palabras, los directivos noveles tienden a focalizar las causas de los incidentes en personas específicas de la institución. 
En cambio, los directivos expertos, reportan una mayor presencia de indignación que de rabia, y esto debido principalmente a la impotencia de no poder manejar ciertas situaciones y sus componentes, los que en su mayoría contienen episodios de violencia.

Esto último también se apoya en el hecho de que la tristeza, como emoción negativa, presenta su mayor diferencia entre noveles y expertos en su forma de frustración y decepción, donde ambas son mayoritarias en el último grupo cuando observan ciertos eventos que son inmanejables o no dependen de ellos, concordando con lo reportado por Del Mastro y Monereo (2014), quienes indican que estos episodios conducen a una actitud de resignación por la falta de recursos para afrontarlos, aunque para la presente investigación, esta actitud evidenció ser producida en mayor medida por los episodios de violencia.

Respecto del efecto de los incidentes críticos sobre el desempeño laboral, se pudo evidenciar que los noveles perciben en $83,3 \%$ de los casos los efectos como "bastante" o "mucho", mientras que solo el $62,9 \%$ de los casos descritos por expertos mostraron tales niveles. Esto se condice con lo obtenido en el análisis cualitativo de la bitácora en línea, donde se observó que los expertos tienen una mayor conciencia de la dificultad de su trabajo y, por consecuencia, tienden a sistematizar en mayor medida los procedimientos, concordando con lo expresado por Norris (1985) en relación con que los expertos automatizan muchas secuencias recurrentes de actividad para resolver los problemas, lo que disminuiría el efecto de los incidentes en su despeño laboral. En los noveles, como ya se mencionó anteriormente, el análisis de las bitácoras también muestra que estos se preocupan más de su imagen de autoridad y, por lo tanto, cualquier cuestionamiento en este sentido es percibido como un efecto negativo a su desempeño.

Al desagregar la intensidad del efecto en el desempeño laboral por tipo de emoción despertada, los datos reflejan que el 82,4\% de las emociones negativas fueron asociadas a efectos de nivel "bastante" y "mucho", mientras que las emociones positivas se asocian completamente a un efecto de nivel "bastante". 
Por otro lado, las emociones mixtas (ambas) tienen solo un $30 \%$ de efecto "bastante" o "mucho", lo que se condice con lo ya mencionado en párrafos anteriores, dado que las emociones negativas son más intensas en un incidente crítico. En cuanto a las emociones positivas, estas solo fueron reportadas en dos casos de incidentes, por lo que no podrían considerarse una tendencia en los resultados y, según el análisis cualitativo, estas estarían asociadas con la solución final del incidente, más que con el incidente en sí mismo.

En cuanto al análisis de los grupos focales, hubo concordancia en los resultados presentes en la bitácora en línea en cuanto a evidenciar que los noveles determinan en mayor medida que las emociones negativas asociadas a las causas de los incidentes son producto de personas específicas del establecimiento, realizando una personificación o considerando su relación con los docentes como causas. Un ejemplo de esta personificación se grafica en esta cita:

hay personas que no deberían estar, sobre todo en nuestras escuelas (directivo novel).

En cambio, en los expertos hay una tendencia a asociar las emociones despertadas con factores más relacionados con el sistema educacional, por lo que sus causas están en mayor medida asociadas con elementos más abstractos y con un menor nivel de juicio hacia las personas. Un ejemplo de este tipo de emoción y juicio lo encontramos en la siguiente cita:

entre toda esa rabia que tenía, pensé que al final mi rabia es con el sistema educacional (directivo experto).

Además, los expertos incluyen preocupaciones basadas en el bienestar de los alumnos y no por su relación personal con los docentes, lo que es relevante, ya que debido a que las emociones pueden ser usadas para priorizar los problemas por solucionar (George, 2000), las preocupaciones manifestadas por los directivos revelan indirectamente el manejo de las emociones en los incidentes críticos. Como ejemplo se puede citar lo siguiente acerca del foco de preocupación: 
Pero el foco no debe ser ese. A mí me puede caer bien uno u otro profesor, pero yo sé que tengo que trabajar con él, porque la finalidad última son los niños (directivo experto).

En relación con las emociones despertadas, los grupos focales determinaron que en ambos tipos de directivos estas son similares, aunque los noveles describen en mayor medida emociones más ambiguas como la confusión y la sorpresa. Esto es destacable, ya que muestra una diferencia respecto de lo reportado en la bitácora en línea, ya que en los grupos focales los expertos manifestaron emociones más negativas. Esto se puede explicar por el hecho de que los expertos son más explícitos en indicar y reconocer las emociones despertadas por los incidentes, es decir, son más autocríticos en su actuar y tienen menos dificultad en relatar sus emociones y valorar o criticar su manejo mediante ellas. Un ejemplo de esto lo encontramos en la siguiente cita:

porque pocas veces en mi año de directora algo me causa tanta rabia, y ese día el otro correo me causa tanta rabia, que yo realmente, yo pienso que actué mal, que yo no debería, por ejemplo, yo levanté la voz (directivo experto).

En el mismo contexto, la reflexión que hacen los directivos en cuanto a los incidentes, el autoconocimiento y el autocontrol, elementos que son parte de un liderazgo eficaz según Rodríguez (2012), están presentes en menor medida en los noveles. Así, salvo por el autocontrol, que está presente en igual medida en ambos grupos, a los noveles les cuesta más determinar la emoción que surge del incidente crítico, siendo esta por lo general ambigua como, por ejemplo aquí:

Y la otra emoción que me dio, bueno aquí hay conflicto, y de la poca tolerancia de la inspectora para decir las cosas, porque también, también se echó la... también se equivocó, siempre hay otra forma, siempre hay otra forma. Entonces, como que me sentí en el fondo, con todas esas cosas mezcladas, la emoción que sentí es que estaba como... yo me sentí incómoda (directivo novel). 
En relación con las estrategias utilizadas para manejar estos incidentes, los noveles reconocieron estar menos preparados en este sentido para afrontar las situaciones conflictivas, en cambio, hay mayor tendencia de los expertos en utilizar elementos de comunicación previamente pensados que permitan manejar de mejor forma estas situaciones:

La verdad es que cuando yo entrevisto alumnos, o entrevisto... trato de que esté o el inspector general, no lo hago nunca solo. Porque es mi palabra contra la de ella. Entonces de repente traigo, tengo de testigo a alguien más, cosa que me ha dado la experiencia, es mejor tener a otra persona y otra voz que también ayude a resolver un poco el problema (directivo experto).

En lo referente al control de emociones, los dos grupos evidenciaron controlarlas ante un incidente crítico y ser conscientes de que deben hacerlo, aunque existe una mayor tendencia de los expertos a dar importancia al hecho de determinar el lugar y los actores adecuados para resolver las situaciones mediante el diálogo.

En el contexto de convivencia escolar, aunque ambos grupos comparten su preocupación por ella, hay una inclinación de los noveles a considerar las consecuencias personales de informar a organismos superiores las situaciones que la afectan, asociando emociones ambiguas a este hecho. Por ejemplo:

Ese tipo de acciones le va a traer consecuencias a ella, entonces... como yo tengo que informar, tuve que informar... me puso en una situación incómoda (directivo novel).

Acerca de los aprendizajes obtenidos, ambos grupos indican haber aprendido a mejorar el manejo y autocontrol de las emociones, apareciendo una diferencia en los expertos que son más capaces de aceptar que ciertos hechos están fuera de su control, lo que concuerda con la bitácora en línea donde este mismo grupo indicó una mayor frustración por no poder resolver estos problemas, aunque con un mayor nivel de resiliencia, como se evidenció en los grupos focales: 
Yo creo que lo que aprendí fue que me pueden decir que no, que no porque le pida algo a un subalterno me va a decir que sí, que no tengo que anticiparme a las respuestas de ellos (directivo experto).

Por último, en relación con la caracterización de los incidentes críticos mencionados por los grupos, para el grupo de noveles en su mayoría estos son derivados de conflictos laborales con antecedentes previos y en su mayoría son producto de la negación a seguir instrucciones, o bien, por diferencias de opinión, mientras que el grupo de expertos hace mención a incidentes que incluyen algún tipo de violencia y que, por lo general, son en menor medida derivados de situaciones conflictivas previas.

\section{Conclusiones}

Sobre la base de lo expuesto, se puede concluir que los expertos tienen un mayor nivel de conciencia en cuanto a las emociones que surgen en los incidentes críticos, un mayor autoconocimiento y una mayor sistematización de sus procedimientos y aprendizajes, lo que les permite percibir un menor efecto de los incidentes críticos en su desempeño laboral. Así, apoyados por una visión no personificada de los problemas, centran sus preocupaciones en aspectos que conllevan al bienestar de la comunidad escolar y no tanto a su imagen o trayectoria profesional.

Por otro lado, el directivo novel asume la resolución de un incidente crítico con sentimientos más negativos y percibe un mayor efecto de estos sucesos en su labor, producto de que su preocupación privilegia su propia imagen de autoridad y su estabilidad laboral.

En este sentido, la trayectoria profesional adquiere una mayor importancia para el directivo novel que para el experto. Los eventos críticos observados por los noveles son mayoritariamente producidos por conflictos que se han mantenido en el tiempo y que, tras alguna situación, se convierten en incidentes críticos; en cambio, para los expertos estos incidentes son por lo general derivados de situaciones de violencia que no provienen directamente de la responsabilidad de 
la institución, aunque muestran —en el contexto de las emociones-, rabia y desilusión cuando no pueden solucionar por sí mismos estos temas, aunque manifiestan un aprendizaje en adquirir resiliencia frente a estas situaciones.

Así mismo, es importante visualizar que los noveles tienen una mayor preocupación por su trayectoria profesional, sin embargo, su menor sistematización de procedimientos, en conjunto con su mayor preocupación por el temor a las consecuencias, hace necesario que algunas técnicas como el análisis de incidentes críticos, le ayuden a gestionar estas situaciones, reflexionar en torno a sus emociones y decisiones para así adquirir una mayor autorregulación de su actuar como directivo frente situaciones críticas.

Al respecto cabe mencionar que los incidentes críticos en el ámbito del liderazgo siempre existirán por la naturaleza del comportamiento humano. Es evidente, entonces, que la aportación de la técnica de análisis de incidentes para los directivos les permitirá acceder al nuevo conocimiento aportado por los otros, el cual se traslapará con el suyo, formándose una nueva perspectiva y aprendizaje que sentarán las bases para una actuación más adecuada y pertinente en el ámbito del liderazgo escolar.

Finalmente, producto del conflicto cognitivo que puede producir este aprendizaje constructivo de tipo social, el directivo podrá ir definiendo su trayectoria profesional y emocional en función de su actuación ante un incidente crítico, lo cual a la luz de la investigación aquí planteada, resultará de gran utilidad, particularmente para los directivos noveles.

\section{Referencias}

Adelson, B. (1984). When novices surpass experts: The difficulty of a task may increase with expertise. Journal of Experimental Psychology: Learning, Memory, and Cognition, 10(3), 483-495. http://dx.doi. org/10.1037/0278-7393.10.3.483

Asociación Nacional de Directivos Escolares de Chile, Andech. (2018). Propuesta carrera directiva. Recuperado de https://www.camara.cl/pdf. aspx?prmID=136169\&prmTIPO=DOCUMENTOCOMISION 
310 LAS EMOCIONES SURGIDAS ANTE UN INCIDENTE CRÍTICO EN EL ÁMBITO DEL LIDERAZGO EFICAZ: ESTUDIO COMPARATIVO ENTRE DIRECTIVOS NOVELES Y EXPERTOS - O. Nail, J. Valdivia, D. Rojas y C. Monereo

Anderson, S. (2011). Desarrollo de las habilidades docentes: implicaciones para el director. Recuperado de https://www.lidereseducativos.cl/wp-content/ uploads/2016/12/NT-1-Desarrollo-de-las-Habilidades-Docentes.pdf

Bereiter, C. \& Scardamalia, M. (1986). Educational relevance of the study of expertise. Interchange, 17(2), 10-19. https://doi.org/10.1007/ BF01807464

Berliner, D. C. (1986). In pursuit of the expert pedagogue. Educational researcher, 15(7), 5-13. https://doi.org/10.3102/0013189X015007007

Bilbao, G. y Monereo, C. (2011). Identificación de incidentes críticos en maestros en ejercicio: propuestas para la formación permanente. Revista Electrónica de Investigación Educativa, 13(1), 135-151. Recuperado de http://redie.uabc.mx/voll3nol/contenido-bilbaomonereo.html

Bisquerra, R. (2009). Psicopedagogía de las emociones. Buenos Aires: Editorial Síntesis.

Bolívar, A. (2009). Una dirección para el aprendizaje. REICE. Revista Iberoamericana Sobre Calidad, Eficacia y Cambio en Educación, 7(1). Recuperado de https://revistas.uam.es/index.php/reice/article/ view/5419

Bush, T. \& Jackson, D. (2002). A preparation for school leadership: International perspectives. Educational Management $\&$ Administration, 30(4), 417-429. https://doi.org/10.1177/0263211X020304004

Butterfield, L. D., Borgen, W. A., Amundson, N. E., \& Maglio, A.-S. T. (2005). Fifty years of the critical incident technique: 1954-2004 and beyond. Qualitative Research, 5(4), 475-497. https://doi. org/10.1177/1468794105056924

Chi, M., Feltovich, P. J., \& Glaser, R. (1981). Categorization and representation of physics problems by experts and novices. Cognitive Science, 5(2), 121-152. https://doi.org/10.1207/s15516709cog0502_2

Corbin, J. \& Strauss, A. (1990). Grounded theory research: Procedures, canons, and evaluative criteria. Qualitative Sociology, 13(1), 3-21. https://doi.org/10.1007/BF00988593

Darling-Hammond, L., LaPointe, M., Meyerson, D., Orr, M. T., \& Cohen, C. (2007). Preparing school leaders for a changing world: Lessons from exemplary leadership development programs. school leadership study. Recuperado de https://edpolicy.stanford.edu/sites/default/files/ publications/preparing-school-leaders-changing-world-lessonsexemplary-leadership-development-programs_1.pdf 
Del Mastro, C. y Monereo, C. (2014). Incidentes críticos en los profesores universitarios de la PUCP. Revista iberoamericana de Educación Superior, 5(13), 3-20. https://doi.org/10.1016/S2007-2872(14)71950-X

Elmore, R. (2010). Mejorando la escuela desde la sala de clases. Santiago de Chile: Fundación Chile.

Everly, G. S. \& Mitchell, J. T. (1997). Critical incident stress managementCISM-: A new era and standard of care in crisis intervention. Ellicott City: Chevron Pub.

Feldman, L. y Blanco, G. (2006). Las emociones en el ambiente laboral: un nuevo reto para las organizaciones. Revista de la Facultad de Medicina, 29(2), 103-108. Recuperado de http://ve.scielo.org/scielo. php?script=sci_arttext\&pid=S0798-04692006000200002\&lng=es\& tlng=es

Fernández-Castro, J. (1999). Las estrategias para afrontar el estrés y la competencia percibida: influencias sobre la salud. En G. Fernández Abascal y F. Palermo (Eds.), Emociones y salud (pp. 364-385). Barcelona: Ariel.

Folkman, S. \& Lazarus, R. (1980). An analysis of coping in a middle-aged community sample. Journal of Health and Social Behavior, 21(3), 219239. https://doi.org/10.2307/2136617

Frijda, N. H. (1993). Moods, emotion episodes, and emotions. En M. Lewis \& J. M. Haviland (Eds.), Handbook of emotions (pp. 381-403). New York: Guilford Press.

Gabarro, J. J. (1987). The dynamics of taking charge. En H. Levinson (Ed.), Designing and managing your career (pp. 122-204). Boston: Harvard Business School Press.

Gajardo, J., Ulloa, J., y Nail, O. (2017). Análisis de incidentes críticos en la sala de clases: una oportunidad de aprendizaje profesional docente (Nota Técnica $\mathrm{N}^{\circ} 7$ ). Recuperado de https://www.lidereseducativos.cl/recursos/ analisis-de-incidentes-criticos-en-la-sala-de-clases-una-oportunidadde-aprendizaje-profesional-docente/

García-Jiménez, E. (1991). Una teoría práctica sobre evaluación. Estudio etnográfico. Sevilla: MIDO.

García-Garduño, J., Slater, C., y López-Gorosave, G. (2011). El director novel: estado del conocimiento y enfoques teóricos educativos. REICE. Revista Iberoamericana Sobre Calidad, Eficacia y Cambio en Educación, 9(3). Recuperado de https://revistas.uam.es/index.php/reice/article/ view/4334 
312 LAS EMOCIONES SURGIDAS ANTE UN INCIDENTE CRÍTICO EN EL ÁMBITO DEL LIDERAZGO EFICAZ: ESTUDIO COMPARATIVO ENTRE DIRECTIVOS NOVELES Y EXPERTOS - O. Nail, J. Valdivia, D. Rojas y C. Monereo

George, J. M. (2000). Emotions and leadership: The role of emotional intelligence. Human Relations, 53(8), 1027-1055. https://doi. org/10.1177/0018726700538001

Hallinger, P. \& Heck, R. H. (1998). Exploring the principal's contribution to school effectiveness: 1980-1995. School Effectiveness and School Improvement, 9(2), 157-191. https://doi. org/10.1080/0924345980090203

Hamui-Sutton, A. y Varela-Ruiz, M. (2013). La técnica de grupos focales. Investigación en Educación Médica, 2(5), 55-60. https://doi.org/10.1016/ S2007-5057(13)72683-8_

Lazarus, R. S. \& Cohen-Charash, Y. (2001). Discrete emotions in organizational life. En R. Payne \& C. Cooper (Eds.), Emotions in organizations (pp. 48-81). Chichester: Wiley.

Leithwood, K., Day, C., Sammons, P., Harris, A., \& Hopkins, D. (2006). Successful school leadership: What is it and how it influences student learning. Research Report 800. Recuperado de: https://www.researchgate.net/ publication/238717790_Successful_School_Leadership_What_It_Is_ and_How_It_Influences_Pupil_Learning

Leithwood, K. (2009). ¿Cómo liderar nuestras escuelas? Aportes desde la investigación. Recuperado de http://ww2.educarchile.cl/UserFiles/ P0038/File/libros/Libro_Liethwood.pdf

Leithwood, K. A. \& Stager, M. (1989). Expertise in principals' problem solving. Educational Administration Quarterly, 25(2), 126-161. https:// doi.org/10.1177/0013161X89025002003

Nail Kröyer, O., Gajardo Aguayo, J., y Muñoz Reyes, M. (2012). La técnica de análisis de incidentes críticos: una herramienta para la reflexión sobre prácticas docentes en convivencia escolar. Psicoperspectivas, 11(2), 56-76. http://doi.org/10.5027/psicoperspectivas-Voll1-Issue2fulltext-204

Navarro Hinojosa, R., López Martínez, A., y Barroso Flores, P. (1998). El análisis de incidentes críticos en la formación inicial de maestros. Revista Electrónica Interuniversitaria de Formación del Profesorado, 1(1), 1-14. Recuperado de http://ww.aufop.com/aufop/uploaded_files/ articulos/1224541140.pdf

Norris, S. P. (1985). Synthesis of research on critical thinking. Educational leadership, 42(8), 40-45. Recuperado de https://eric. ed.gov/?id=EJ319814

Monereo, C. y Badía, A. (2011). Los heterónimos del docente: identidad, selfs y enseñanza. En C. Monereo y J. Pozo (Eds.), La identidad en 
psicología de la educación. Necesidad, utilidad y límites (pp. 59-77). Madrid: Narcea.

Monereo, C., Weise, C., y Álvarez, I. (2013). Cambiar la identidad docente en la universidad. Formación basada en incidentes dramatizados. Infancia y Aprendizaje, 36(3), 323-340. https://doi. org/10.1174/021037013807533043

Pont, B., Nusche, D., \& Moorman, H. (2008). Improving school leadership, Volume 1: Policy and practice. Recuperado de https://www.oecd.org/ edu/school/44374889.pdf

Robinson, V. M., Hohepa, M., \& Lloyd, C. (2007). School leadership and student outcomes: Identifying what works and why. Winmalee: Australian Council for Educational Leaders.

Rodríguez, S. (2012). Liderazgo y desarrollo de docentes: revisión de incidentes críticos registrados por un grupo de participantes de un programa de formación de líderes escolares. En O. Nail (Ed.), Análisis de incidentes críticos de aula (pp. 99-119). Santiago de Chile: RIL Editores.

Sockman, B. R. \& Sharma, P. (2008). Struggling toward a transformative model of instruction: It's not so easy! Teaching and Teacher Education, 24(4), 1070-1082. https://doi.org/10.1016/j.tate.2007.11.008

Stake, R. (1995). The art of case study research. Illinois: Sage Publications.

Tripp, D. (2011). Critical incidents in teaching: Developing professional judgement. Nueva York: Routledge.

Uribe, M. y Celis, M. (2012). Desarrollo de capacidades para un liderazgo escolar efectivo: del levantamiento de competencias al reconocimiento de buenas prácticas. En J. Weinstein. \& G. Muñoz (Eds.), ¿Qué sabemos de los directores de escuela en Chile? (pp. 111-134). Santiago de Chile: Salesianos Impresores S. A.

Voss, J. F., Greene, T. R., Post, T. A., \& Penner, B. C. (1983). Problem-solving skill in the social sciences. En G. H. Bower (Ed.), Psychology of learning and motivation (pp. 165-213). Stanford: Academic Press. https://doi. org/10.1016/S0079-7421(08)60099-7

Waters, T., Marzano, R. J., \& McNulty, B. (2003). Balanced leadership. What 30 years of research tells us about the effect of leadership on student achievement: A working paper. Recuperado de https://files.eric.ed.gov/ fulltext/ED481972.pdf

West-Burnham, J. \& Ireson, J. (2005). Leadership development and personal effectiveness. Recuperado de https://dera.ioe.ac.uk/5952/1/downlo 
ad\%3fid=17238\&filename=leadership-development-and-personaleffectiveness.pdf

Weindling, D. (1999). Stages of headship. En T. Bush, L. Bell, R. Bolam, R. Glatter, \& P. Ribbins (Eds.), Educational management. Redefining theory, policy and practice (pp. 90-101). London: Paul Chapman Publishing. http://dx.doi.org/10.4135/9781446219676.n7

Woods, P. (1997). Experiencias críticas en la enseñanza y el aprendizaje. Barcelona: Paidós.

Zoro, B. y Castro, G. (2016). ¿Cómo puedo gestionar las emociones en las escuelas? Recuperado de https://www.lidereseducativos.cl/recursos/ como-puedo-gestionar-las-emociones-en-las-escuelas/

Recibido: 20/04/2019

Aceptado: 07/11/2019 